\title{
Scintillation Properties of Li-doped ZnO Translucent Ceramic
}

\author{
Toshiaki Kunikata, ${ }^{*}$ Takumi Kato, Daiki Shiratori, \\ Daisuke Nakauchi, Noriaki Kawaguchi, and Takayuki Yanagida \\ Nara Institute of Science and Technology, 8916-5 Takayama, Ikoma, Nara 630-0192, Japan
}

(Received October 8, 2021; accepted November 1, 2021)

Keywords: Li-doped $\mathrm{ZnO}$, scintillation, translucent ceramic, annealing effect, lattice defects

We synthesized a $0.1 \% \mathrm{Li}$-doped $\mathrm{ZnO}$ translucent ceramic using spark plasma sintering (SPS) and annealed it at 700 or $800{ }^{\circ} \mathrm{C}$ in air. The photoluminescence (PL) and scintillation properties of all samples were evaluated. The PL quantum yield $(Q Y)$ and scintillation light yield $(L Y)$ were improved by annealing owing to the reduction in the number of oxygen defects in comparison with the as-prepared sample. Among the translucent ceramic samples, the sample annealed at $700{ }^{\circ} \mathrm{C}$ showed the highest $L Y(5800 \mathrm{ph} / 5.5 \mathrm{MeV}-\alpha)$; the scintillation $L Y$ was lower in the sample annealed at $800{ }^{\circ} \mathrm{C}$ because of the increase in the number of trap sites.

\section{Introduction}

Inorganic scintillators, which convert high-energy photons ${ }^{(1)}$ or particles ${ }^{(2)}$ with an energy of $\mathrm{keV}$ to $\mathrm{MeV}$ into lower-energy photons, have been playing a major role in many fields of radiation detection, including astrophysics, ${ }^{(3)}$ medical imaging, ${ }^{(4)}$ security, ${ }^{(5)}$ resource exploration, ${ }^{(6)}$ environmental monitoring, ${ }^{(7)}$ and biology. ${ }^{(8)}$ Generally, scintillators are combined with photodetectors. ${ }^{(9)}$ When radiation interacts with a scintillator, the scintillator converts the energy of the ionizing radiation to low-energy photons. After these photons are converted to electrons by the photodetector, an electrical signal flows into an electrical circuit, and a computer performs a detailed analysis of the signal.

Scintillators for $\alpha$-ray detection have been used in nuclear facilities, where uranium and plutonium, which emit $\alpha$-rays, must be monitored because their absorption by workers could seriously affect their health. Materials with an intermediate effective atomic number $\left(Z_{\text {eff }}=10-\right.$ 30) are used as scintillators for $\alpha$-ray detection because they do not easily detect environmental $\gamma$-rays and background neutrons. Thus, Ag-doped $\mathrm{ZnS}(\mathrm{ZnS}: \mathrm{Ag}$ ) has been applied in most scintillation detectors for $\alpha$-rays for many years. ${ }^{(10)}$ However, $\mathrm{ZnS}: \mathrm{Ag}$ is only available as a white polycrystalline powder and must be sprayed on thin opaque screens, resulting in its energy resolution being insufficient to separate various radioisotopes. ${ }^{(11)}$ One of the reasons for the low energy resolution of $\mathrm{ZnS}: \mathrm{Ag}$ is its opacity, and alternative materials with high transmittance are desirable to achieve a higher energy resolution.

*Corresponding author: e-mail: kunikata.toshiaki.kt1@ms.naist.jp https://doi.org/10.18494/SAM3683 
$\mathrm{ZnO}$ is a promising next-generation $\alpha$-ray detector since $Z_{\text {eff }}$ of $\mathrm{ZnO}$ is close to that of $\mathrm{ZnS}: \mathrm{Ag}$. $\mathrm{ZnO}$ has mostly been studied for its use in semiconductor devices such as LEDs, ${ }^{(12)}$ although other phosphor applications, including scintillators, are expected, similarly to other semiconductor materials such as $\mathrm{GaN}^{(13)}$ and $\mathrm{Ga}_{2} \mathrm{O}_{3} \cdot{ }^{(14)} \mathrm{In}$ terms of its scintillation properties, $\mathrm{ZnO}$ shows two types of luminescence: sub-nanosecond luminescence due to free excitons at around $390 \mathrm{~nm}^{(15)}$ and microsecond-order luminescence due to lattice defects in the visible region. ${ }^{(16)}$ Some researchers have explored luminescence due to free excitons and reported a scintillation light yield $(L Y)$ of In-doped $\mathrm{ZnO}$ thin film of $625 \mathrm{ph} / 5.5 \mathrm{MeV}-\alpha^{(17-19)}$ However, detectors do not always require such a fast response from free excitons. For example, the scintillation of $\mathrm{ZnS}: \mathrm{Ag}$ has a decay time constant of microsecond order. ${ }^{(20)}$ On the other hand, other researchers have reported a scintillation $L Y$ due to the lattice defects of Cd-doped $\mathrm{ZnO}$ thin film of $18000 \mathrm{ph} / 5.5 \mathrm{MeV}-\alpha{ }^{(21)}$ In most environments in which $\alpha$-ray scintillation detectors are employed, the counting rate of $\alpha$-rays is not high, and microsecond-order decay is acceptable. Thus, $\mathrm{ZnO}$ with enhanced lattice-defect luminescence is potentially suitable for this application.

In this study, we focused on a translucent ceramic, ${ }^{(22-24)}$ a new material form of scintillators that can be used to enhance lattice-defect luminescence. Translucent ceramics have more lattice defects than other material forms such as single crystals, ${ }^{(25,26)}$ which are generally used as scintillators; thus, $\mathrm{ZnO}$ translucent ceramics may have enhanced $L Y$. Moreover, it was previously reported that the introduction of $\mathrm{Li}$ increased the concentration of lattice defects and enhanced the photoluminescence (PL) properties of $\mathrm{ZnO}$ films. ${ }^{(27)}$ Thus, Li doping into $\mathrm{ZnO}$ may also enhance scintillation properties. In addition, it has been reported that annealing regulated the amount of lattice defects in $\mathrm{ZnO}$ and enhanced the lattice-defect luminescence. ${ }^{(16,28)}$ Therefore, we prepared $0.1 \%$ Li-doped $\mathrm{ZnO}$ translucent ceramic by spark plasma sintering (SPS) and annealed samples in air, then evaluated their PL and scintillation properties.

\section{Materials and Methods}

\subsection{Sample preparation}

The Li-doped $\mathrm{ZnO}$ translucent ceramic was synthesized by SPS (SinterLand LabX-100) in a vacuum. ${ }^{(29)}$ First, raw powders of $\mathrm{ZnO}\left(99.99 \%\right.$, Kojundo Chemical) and $\mathrm{Li}_{2} \mathrm{CO}_{3}$ (99.99\%, Rare Metallic) were mixed with a mortar and pestle. The mass of the mixture was $0.5 \mathrm{~g}$ and the $\mathrm{Li}$ concentration was fixed to $0.1 \mathrm{~mol} \%$. Then, the Li-doped $\mathrm{ZnO}$ powder was poured into a cylindrical graphite die with a hole of $10.4 \mathrm{~mm}$ diameter, which was held between two graphite punches. The sintering sequence was as follows. First, the temperature was increased from 20 to $600{ }^{\circ} \mathrm{C}$ in $5 \mathrm{~min}$, then kept at $600^{\circ} \mathrm{C}$ for 5 min under a pressure of $13 \mathrm{MPa}$. Next, the sintering temperature was increased from 600 to $1100{ }^{\circ} \mathrm{C}$ in $50 \mathrm{~min}$ and kept at $1100{ }^{\circ} \mathrm{C}$ for $20 \mathrm{~min}$ under a pressure of $100 \mathrm{MPa}$. After the sintering, the surface of the translucent ceramic was polished using a polishing machine (MetaServ 250, BUEHLER), after which the thickness of the translucent ceramic was approximately $0.5 \mathrm{~mm}$. Then, we divided the translucent ceramic into three pieces, two of which were annealed for $24 \mathrm{~h}$ in air, one at $700{ }^{\circ} \mathrm{C}$ and the other at $800{ }^{\circ} \mathrm{C}$. 


\subsection{Evaluation methods}

Diffuse transmittance spectra from 300 to $800 \mathrm{~nm}$ were evaluated using a spectrophotometer (SolidSpec-3700, Shimadzu). PL quantum yields ( $Q Y$ s) were recorded using a Quantaurus-QY spectrometer (C11347, Hamamatsu Photonics). PL excitation and emission spectra from 300 to $700 \mathrm{~nm}$ were measured using a spectrofluorometer (FP-8600, JASCO). PL decay curves were measured using a Quantaurus- $\tau$ spectrometer (C11367, Hamamatsu).

X-ray-induced scintillation spectra in the range of 300-690 nm were measured using our original setup. ${ }^{(30)}$ An X-ray generator (XRB80P\&N200X4550, Spellman) was used as the excitation source. The applied tube voltage and current were $80 \mathrm{kV}$ and $1.2 \mathrm{~mA}$, respectively. During irradiation, the scintillation photons were guided into a spectrometer (Andor DU-420BU2 CCD with a Shamrock 163 monochromator) through an optical fiber. X-ray-induced scintillation decay curves were evaluated using our original setup. ${ }^{(31)}$ To determine the scintillation $L Y$ s induced by $5.5 \mathrm{MeV} \alpha$-rays from ${ }^{241} \mathrm{Am}$, the pulse-height spectra were measured using our original system with a shaping time of $5 \mu \mathrm{s} .{ }^{(32)}$ To calculate scintillation $L Y \mathrm{~s}$ of the Lidoped $\mathrm{ZnO}$ samples, we compared them with that of Ce-doped $\mathrm{Y}_{3} \mathrm{Al}_{5} \mathrm{O}_{12}$ (YAG:Ce) as a reference sample $(12000 \mathrm{ph} / 5.5 \mathrm{MeV}-\alpha)^{(33)}$ because YAG:Ce has a similar emission wavelength to that of the lattice-defect luminescence of $\mathrm{Li}$-doped $\mathrm{ZnO}$.

Thermally stimulated luminescence (TSL) glow curves were evaluated using a TSL reader (TL-2000, Nanogray Inc.). The Li-doped ZnO samples were irradiated by X-rays of 10 Gy before measuring the TSL glow curve. The measured temperature range was from 50 to $400{ }^{\circ} \mathrm{C}$.

\section{Results and Discussion}

Figures 1(a) and 1(b) show the samples under room light and UV light illumination (365 nm), respectively. Hereinafter, the Li-doped $\mathrm{ZnO}$ sample annealed at $700{ }^{\circ} \mathrm{C}\left(800{ }^{\circ} \mathrm{C}\right)$ is referred to as the $700{ }^{\circ} \mathrm{C}\left(800^{\circ} \mathrm{C}\right)$ sample. The annealed samples were transparent to the naked eye, and the color changed from dark brown before annealing to light green after annealing. The annealed samples clearly showed orange luminescence under UV illumination at $365 \mathrm{~nm}$. The color of the undoped sample was slightly lighter than that of the Li-doped samples.

Figure 2 shows the diffuse transmittance spectra of the samples. The annealed samples showed an optical absorption edge at $400 \mathrm{~nm}$, which roughly coincided with the bandgap of $\mathrm{ZnO}$. An absorption band was observed from 400 to $550 \mathrm{~nm}$ in the as-prepared sample but

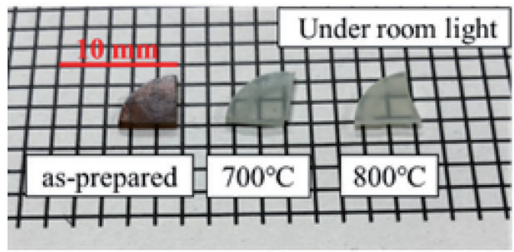

(a)

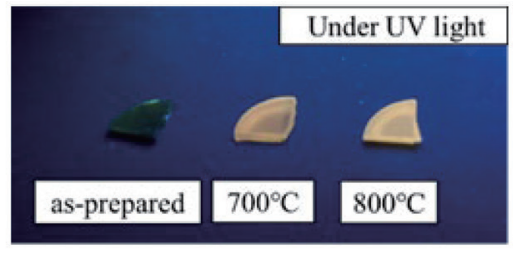

(b)

Fig. 1. (Color online) Li-doped $\mathrm{ZnO}$ samples under (a) room light and (b) UV light at $365 \mathrm{~nm}$. 


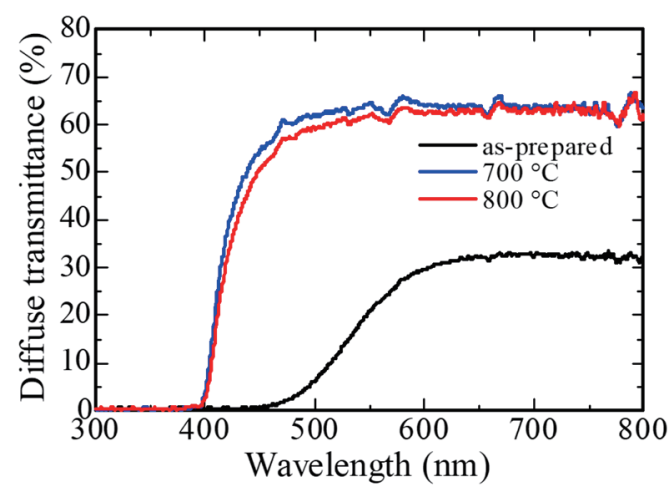

Fig. 2. (Color online) Diffuse transmittance spectra of Li-doped $\mathrm{ZnO}$ samples.

not in the annealed samples. This absorption was due to oxygen defects ${ }^{(34)}$ and resulted in the brown color of the as-prepared sample, as shown in Fig. 1(a).

Figure 3 shows the PL excitation and emission spectra. All the samples showed excitation peaks at around $390 \mathrm{~nm}$ and broad emission peaks at around $500 \mathrm{~nm}$. Judging from the emission peak positions, the emission peaks were due to lattice defects. ${ }^{(15)}$ For the annealed samples, the excitation and emission peaks were at slightly longer and shorter wavelengths than those of the as-prepared sample, respectively. The $Q Y$ s of the 700 and $800{ }^{\circ} \mathrm{C}$ samples were 4.2 and $5.4 \%$, respectively, and the $Q Y$ of the as-prepared sample was below the detection limit (1\%) of the instrument. The annealing effect increased the $Q Y$ of the Li-doped $\mathrm{ZnO}$ translucent ceramic samples because of the decreased self-absorption. The emission peak at around $500 \mathrm{~nm}$ overlapped with the absorption peak at 400-550 $\mathrm{nm}$ observed in the diffuse transmittance spectra; thus, the lattice-defect luminescence of the as-prepared sample was strongly affected by the self-absorption. The self-absorption also caused the peak shifts in the PL excitation and emission spectra.

The PL decay curves of the samples are illustrated in Fig. 4. The excitation wavelength was $405 \mathrm{~nm}$, whereas the monitored emission wavelength was $500 \mathrm{~nm}$. The decay curves of the annealed samples were approximated by a sum of three exponential decay functions. The $700{ }^{\circ} \mathrm{C}$ sample had decay time constants of $0.432,1.664$, and $9.283 \mu$ s, and the $800{ }^{\circ} \mathrm{C}$ sample had decay time constants of $0.391,2.350$, and $18.633 \mu \mathrm{s}$. On the other hand, the decay curve of the asprepared sample was not detected owing to the low luminescence intensity. The obtained decay time constants were on the order of microseconds. These values were in approximate agreement with thoes in previous reports. ${ }^{(15)}$ The decay curve was composed of three components corresponding to the different types of lattice defect. ${ }^{(15)}$ However, the specific types of lattice defect corresponding to the three components were unclear because several types of lattice defect have similar emission wavelengths according to previous studies. ${ }^{(16,34)}$

X-ray-induced scintillation spectra of the samples are illustrated in Fig. 5. All the samples showed scintillation peaks between 500 and $550 \mathrm{~nm}$. The scintillation peak positions of the annealed samples shifted to the shorter-wavelength side with a larger shift than that observed in the PL emission spectra. This was because of the transmission-type measurement geometry 


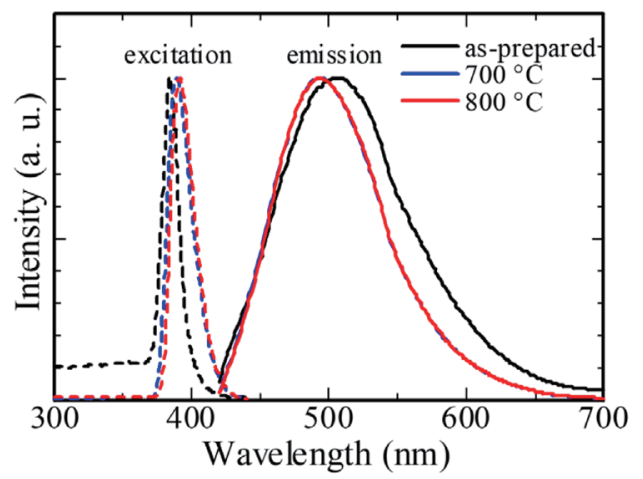

Fig. 3. (Color online) PL excitation and emission spectra of Li-doped $\mathrm{ZnO}$ samples.

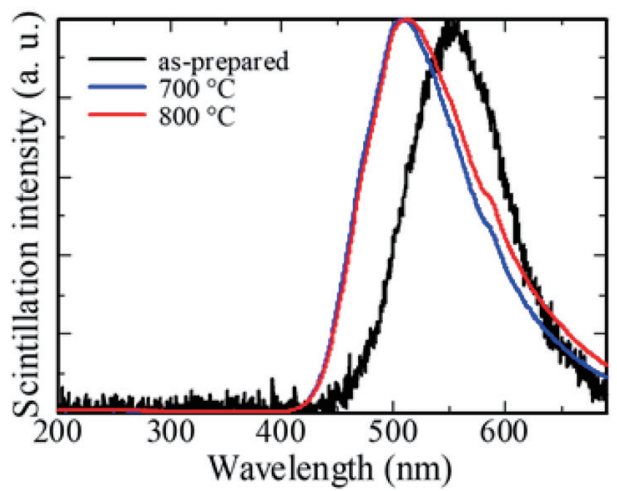

Fig. 5. (Color online) Scintillation spectra of Lidoped $\mathrm{ZnO}$ samples under X-ray irradiation.

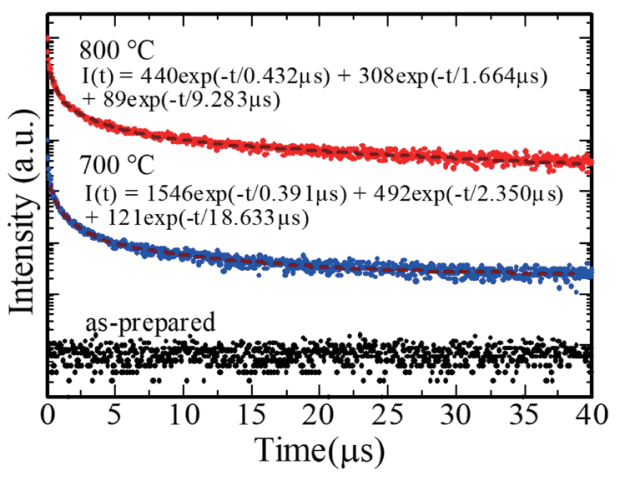

Fig. 4. (Color online) PL decay curves of Li-doped $\mathrm{ZnO}$ samples.

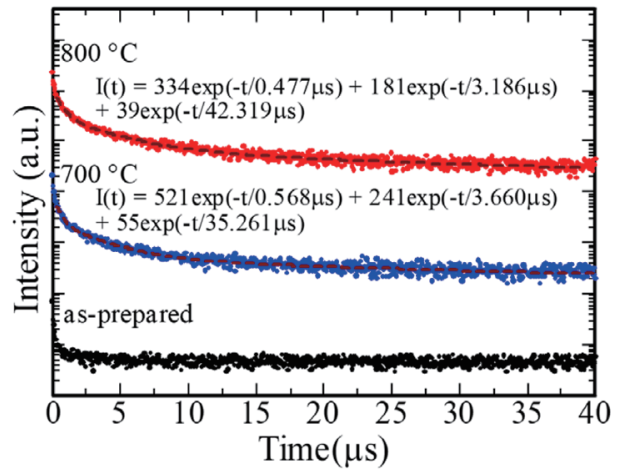

Fig. 6. (Color online) Scintillation decay curves of Li-doped $\mathrm{ZnO}$ samples under X-ray irradiation.

used to measure the scintillation spectra, whereas that used to measure the PL spectra was the reflection type. Hence, scintillation is strongly influenced by self-absorption. On the other hand, no exciton luminescence at around $390 \mathrm{~nm}$ was observed in all the samples since the excitation wavelength of the lattice-defect luminescence overlaps with the emission wavelength of the exciton luminescence.

X-ray-induced scintillation decay curves of all the samples are shown in Fig. 6. No decay curve was detected for the as-prepared sample because of the low luminescence intensity. The scintillation decay curves of the annealed samples were approximated by a sum of three exponential decay functions in the same manner as for the PL curves. The $700{ }^{\circ} \mathrm{C}$ sample had decay time constants of $0.477,3.186$, and $42.319 \mu$ s, and the $800{ }^{\circ} \mathrm{C}$ sample had decay time constants of $0.568,3.660$, and $35.261 \mu \mathrm{s}$. All the scintillation decay time constants were longer than those for the PL, which can be explained by the different luminescence mechanisms of PL and scintillation. The PL mechanism involves excitation and relaxation processes only at luminescence centers, whereas the scintillation mechanism also includes an energy migration process. Because of this additional process, the scintillation decay time constants are generally longer than those for the PL. 


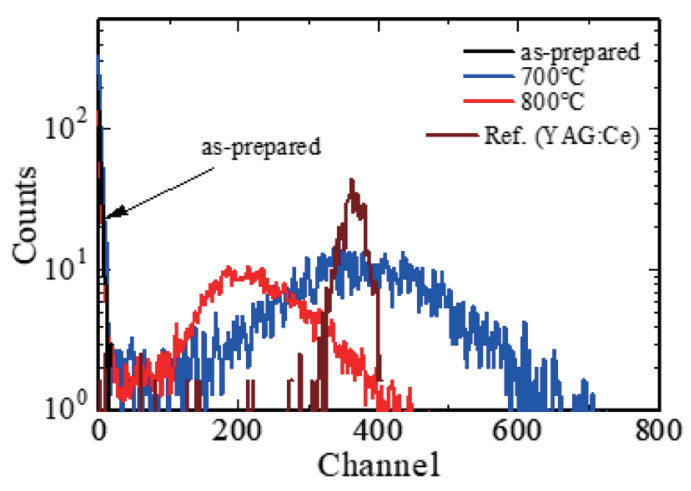

Fig. 7. (Color online) Pulse-height spectra under 241Am $\alpha$-ray irradiation of $\mathrm{Li}$-doped $\mathrm{ZnO}$ samples and YAG:Ce as a reference.

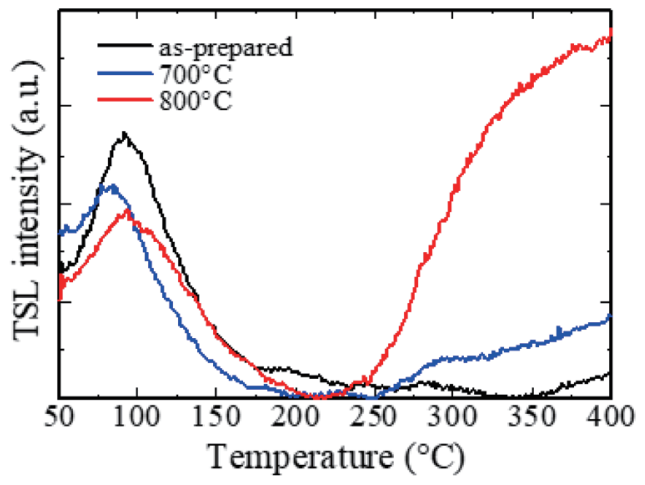

Fig. 8. (Color online) TSL glow curves of Li-doped $\mathrm{ZnO}$ samples.

Pulse-height spectra of the samples under $\alpha$-ray irradiation from ${ }^{241} \mathrm{Am}$ are presented in Fig. 7. Full energy absorption peaks could not be detected for the as-prepared sample. On the other hand, full energy absorption peaks were observed for the annealed samples. The 700 and $800{ }^{\circ} \mathrm{C}$ samples showed $L Y \mathrm{~S}$ of 5,800 and 3,700 ph/5.5 MeV- $\alpha$, respectively. These values were higher than that of In-doped $\mathrm{ZnO}$ thin film $(625 \mathrm{ph} / 5.5 \mathrm{MeV}-\alpha)^{(17)}$ but lower than that of Cd-doped $\mathrm{ZnO}$ thin film $(18000 \mathrm{ph} / 5.5 \mathrm{MeV}-\alpha) \cdot{ }^{(21)}$ The $700{ }^{\circ} \mathrm{C}$ sample showed a higher $L Y$ than the $800{ }^{\circ} \mathrm{C}$ sample despite the $800{ }^{\circ} \mathrm{C}$ sample having the higher $Q Y$. The phenomenological model of the scintillation mechanism can explain this phenomenon. The $L Y$ depends on not only the efficiency at luminescence centers (PL $Q Y$ ) but also the energy migration efficiency from the host to the luminescence centers and the band gap energy. ${ }^{(35)}$ Therefore, a higher $Q Y$ does not necessarily result in a higher $L Y$.

To evaluate the energy migration efficiency indirectly, TSL glow curves were measured. Figure 8 shows TSL glow curves of the samples irradiated with X-rays at $10 \mathrm{~Gy}$. All the samples showed a glow peak at around $100{ }^{\circ} \mathrm{C}$, and the TSL intensity slightly decreased upon annealing. On the other hand, the TSL intensity at $250{ }^{\circ} \mathrm{C}$ was much higher for the $800{ }^{\circ} \mathrm{C}$ sample than for the $700{ }^{\circ} \mathrm{C}$ sample. The $800{ }^{\circ} \mathrm{C}$ sample exhibited the largest value of the TSL intensity integrated from 50 to $400{ }^{\circ} \mathrm{C}$. The TSL intensity is related to the number of trap sites; thus, this result suggests that the $800{ }^{\circ} \mathrm{C}$ sample has the largest number of trap sites among the three samples. These trap sites deteriorate the energy migration efficiency; thus, the scintillation $L Y$ of the 800 ${ }^{\circ} \mathrm{C}$ sample was suppressed regardless of its higher PL QY. Although we cannot definitively conclude the origin of the trap sites, judging from the transmittance spectra and TSL glow curves, the trap sites at $100{ }^{\circ} \mathrm{C}$ may be due to oxygen defects.

\section{Conclusions}

We synthesized a $0.1 \%$ Li-doped $\mathrm{ZnO}$ translucent ceramic by SPS. The Li-doped $\mathrm{ZnO}$ translucent ceramic showed only lattice-defect luminescence in its PL and scintillation properties. Annealing increased the PL $Q Y$ and scintillation $L Y$ because it suppressed self- 
absorption. The translucent ceramic annealed at $700{ }^{\circ} \mathrm{C}$ showed the highest scintillation $L Y$; the lower scintillation in the translucent ceramic annealed at $800{ }^{\circ} \mathrm{C}$ was due to the increased number of trap sites.

\section{Acknowledgments}

This work was supported by Grants-in-Aid for Scientific Research B (19H03533, 21H03733, and 21H03736), Early-Career Scientists (20K15026 and 20K20104), and JSPS Fellows (20J23225) from the Japan Society for the Promotion of Science. The Cooperative Research Project of the Research Center for Biomedical Engineering, Yashima Environment Technology Foundation, Okura Kazuchika Foundation, and Hitachi Metals-Materials Science Foundation are also acknowledged.

\section{References}

1 Y. Fujimoto, K. Saeki, D. Nakauchi, T. Yanagida, M. Koshimizu, and K. Asai: Sens. Mater. 31 (2019) 1241.

2 N. Kawaguchi, H. Kimura, M. Akatsuka, G. Okada, N. Kawano, K. Fukuda, and T. Yanagida: Sens. Mater. 30 (2018) 1585.

3 H. Kimura, F. Nakamura, T. Kato, D. Nakauchi, G. Okada, N. Kawaguchi, and T. Yanagida: J. Mater. Sci. Mater. Electron. 29 (2018) 8498.

4 Q. Liu, Y. Cheng, Y. Yang, Y. Peng, H. Li, Y. Xiong, and T. Zhu: Appl. Radiat. Isot. 163 (2020) 109217.

5 I. Kanno, R. Imamura, Y. Yamashita, M. Ohtaka, M. Hashimoto, K. Ara, and H. Onabe: Jpn. J. Appl. Phys. 53 (2014) 056601.

6 C. L. Melcher: Nucl. Inst. Methods Phys. Res., Sect. B 40-41 (1989) 1214.

7 K. Watanabe, T. Yanagida, and K. Fukuda: Sens. Mater. 27 (2015) 269.

8 T. Matsubara, T. Yanagida, N. Kawaguchi, T. Nakano, J. Yoshimoto, M. Sezaki, H. Takizawa, S. P. Tsunoda, S. ichiro Horigane, S. Ueda, S. Takemoto-Kimura, H. Kandori, A. Yamanaka, and T. Yamashita: Nat. Commun. 12 (2021) 4097.

9 T. Yanagida: Opt. Mater. (Amst). 35 (2013) 1987.

10 S. A. McElhaney, J. A. Ramsey, M. L. Bauer, and M. M. Chiles: IEEE Trans. Nucl. Sci. 37 (1990) 868.

11 M. Toribio, J. F. García, A. Izquierdo-Ridorsa, R. Tauler, and G. Rauret: Anal. Chim. Acta 310 (1995) 297.

12 K. Nakahara, S. Akasaka, H. Yuji, K. Tamura, T. Fujii, Y. Nishimoto, D. Takamizu, A. Sasaki, T. Tanabe, H. Takasu, H. Amaike, T. Onuma, S. F. Chichibu, A. Tsukazaki, A. Ohtomo, and M. Kawasaki: Appl. Phys. Lett. 97 (2010) 013501.

13 T. Yanagida, T. Kato, D. Nakauchi, G. Okada, and N. Kawaguchi: Appl. Phys. Express 14 (2021) 082006.

14 T. Yanagida, G. Okada, T. Kato, D. Nakauchi, and S. Yanagida: Appl. Phys. Express 9 (2016) 042601.

15 E. I. Gorokhova, S. B. Eron'ko, E. A. Oreshchenko, A. V. Sandulenko, P. A. Rodnyı̆, K. A. Chernenko, I. D. Venevtsev, A. M. Kul'kov, F. Muktepavela, and P. Boutachkov: J. Opt. Technol. 85 (2018) 729.

16 E. I. Gorokhova, G. V. Ananieva, S. B. Eron'ko, E. A. Oreschenko, P. A. Rodnyi, K. A. Chernenko, I. V. Khodyuk, E. P. Lokshin, G. B. Kunshina, O. G. Gromov, and K. P. Loot: J. Opt. Technol. 78 (2011) 753.

17 T. Yanagida, Y. Fujimoto, A. Yoshikawa, Y. Yokota, M. Miyamoto, H. Sekiwa, J. Kobayashi, T. Tokutake, K. Kamada, and S. Maeo: IEEE Trans. Nucl. Sci. 57 (2010) 1325.

18 K. A. Chernenko, E. I. Gorokhova, S. B. Eronko, A. V. Sandulenko, I. D. Venevtsev, H. Wieczorek, and P. A. Rodnyi: IEEE Trans. Nucl. Sci. 65 (2018) 2196.

19 K. A. C. Hernenko, I. D. V Enevtsev, A. M. K. U. L. Kov, F. A. M. Uktepavela, and P. L. B. Outachkov: J. Opt. Technol. 85 (2018) 729.

20 N. Kubota, M. Katagiri, K. Kamijo, and H. Nanto: Nucl. Instrum. Methods Phys. Res., Sect. A 529 (2004) 321.

21 T. Yanagida, Y. Fujimoto, M. Miyamoto, and H. Sekiwa: Jpn. J. Appl. Phys. 53 (2014) 02BC13.

22 T. Kato, D. Nakauchi, N. Kawaguchi, and T. Yanagida: Sens. Mater. 32 (2020) 1411.

23 H. Kimura, T. Kato, D. Nakauchi, N. Kawaguchi, and T. Yanagida: Sens. Mater. 33 (2021) 2187.

24 H. Kimura, T. Kato, D. Nakauchi, N. Kawaguchi, and T. Yanagida: Sens. Mater. 32 (2020) 1381.

25 Y. Takebuchi, H. Fukushima, T. Kato, D. Nakauchi, N. Kawaguchi, and T. Yanagida: Sens. Mater. 32 (2020) 1405 . 
26 D. Nakauchi, T. Kato, N. Kawaguchi, and T. Yanagida: Sens. Mater. 33 (2021) 2203.

27 M. Hjiri, M. S. Aida, O. M. Lemine, and L. El Mir: Mater. Sci. Semicond. Process. 89 (2019) 149.

28 P. Rodnyi, K. Chernenko, O. Klimova, V. Galkin, A. Makeenko, E. Gorokhova, D. Buettner, W. Keur, and H. Wieczorek: Radiat. Meas. 90 (2016) 136.

29 T. Kato, N. Kawano, G. Okada, N. Kawaguchi, and T. Yanagida: Nucl. Instrum. Methods Phys. Res., Sect. B 435 (2018) 296.

30 T. Yanagida, K. Kamada, Y. Fujimoto, H. Yagi, and T. Yanagitani: Opt. Mater. (Amst). 35 (2013) 2480.

31 T. Yanagida, Y. Fujimoto, T. Ito, K. Uchiyama, and K. Mori: Appl. Phys. Express 7 (2014) 3.

32 T. Yanagida, Y. Fujimoto, M. Arai, M. Koshimizu, T. Kato, D. Nakauchi, and N. Kawaguchi: Sens. Mater. 32 (2020) 1351.

33 H. Takahashi, T. Yanagida, D. Kasama, T. Ito, M. Kokubun, K. Makishima, T. Yanagitanit, H. Yagi, T. Shigeta, and T. Ito: IEEE Nucl. Sci. Symp. Conf. Rec. 3 (2005) 1337.

34 P. A. Rodnyi, K. A. Chernenko, E. I. Gorokhova, S. S. Kozlovskii, V. M. Khanin, and I. V. Khodyuk: IEEE Trans. Nucl. Sci. 59 (2012) 2152.

35 T. Igashira, N. Kawano, G. Okada, N. Kawaguchi, and T. Yanagida: Opt. Mater. (Amst) 79 (2018) 232. 